\title{
REVIEW OF MEVVA ION SOURCE PERFORMANCE FOR ACCELERATOR INJECTION
}

\author{
I. G. Brown and X. Godecho** \\ Litwrence Berkeley Laboratory \\ Berkeley, CA 94720) \\ and \\ P. Spädtke, H. Emig, D. M. Rück and B. H. Wolf \\ Gesellschaft für Schwerionenforschung (GSI) \\ Postfach 110552, 6100 Darmstadt, Germany \\ Presented at the \\ JEEE Particle Accelerator Conference \\ San Francisco, CA \\ May 6-9, 1991
}

* On leave to Lawrence Berkeley Laboratory from SODERN; present address SODERN, 1 Ave. Descartes, 94451 Limeil-Brevannes, France. Supponed by a grant from the French Ministere des Affaires Etrangeres, Bourse Lavoisier, and a grant from SODERN.

This work was underiaken as part of an ongoing collaboration betwien the Lawrence Berke ley Laboratory and The Gesellschaft für Sch werionenforschung. That part of the work that was carried out at I.BL was supponted in part by the U.S. Army Research Office under Contract No. ARO 1 16-89, the Office of Naval Resarch under Contract No. 88-F-

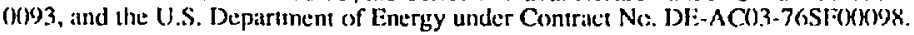




\title{
REVIEW OF MEVVA ION SOURCE PERFORMANCE FOR ACCELERATOR INJECTION
}

\author{
I. G. Brown and X. Godechot* \\ Lawrence Berkeley Laboratory \\ Berkeley, CA 94720
}

\author{
and
P. Spädtke, H. Emig, D. M. Rück and B. H. Wolf
Gesellschaft für Schwerionenforschung (GSI) \\ Postfach 110552, 6100 Darmstadt, Germany
}

\begin{abstract}
The Mevva (metal vapor vacuum arc) ion source provides high current beams of multiply-charged metal ions suitable for use in heavy ion synchrotrons as well as for melallurgical ion implantation. Pulsed beam currents of up to several amperes can be produced at ion energies of up to several hundred keV. Operation has been demonstrated for 48 metallic ion species: $\mathrm{Li}, \mathrm{C}, \mathrm{Mg}, \mathrm{Al}, \mathrm{Si}, \mathrm{Ca}, \mathrm{Sc}, \mathrm{Ti}, \mathrm{V}, \mathrm{Cr}, \mathrm{Mn}, \mathrm{Fe}, \mathrm{Co}, \mathrm{Ni}, \mathrm{Cu}$, $\mathrm{Zn}, \mathrm{Ge}, \mathrm{Sr}, \mathrm{Y}, \mathrm{Zr}, \mathrm{Nb}, \mathrm{Mo}, \mathrm{Pd}, \mathrm{Ag}, \mathrm{Cd}, \mathrm{In}, \mathrm{Sn}, \mathrm{Ba}, \mathrm{La}, \mathrm{Ce}$, $\mathrm{Pr}, \mathrm{Nd}, \mathrm{Sm}, \mathrm{Gd}, \mathrm{Dy}, \mathrm{Ho}, \mathrm{Er}, \mathrm{Yb}, \mathrm{Hf}, \mathrm{Ta}, \mathrm{W}, \mathrm{Ir}, \mathrm{Ph}, \mathrm{Au}, \mathrm{Pb}$, $B i, T h$ and $U$. When the source is operated optimally the rms fractional beam noise can be as low as $7 \%$ of the mean beam current: and when properly triggered the source operates reliably and reproducibly for many tens of thousands of putses without failure. In this paper we review the source performance referred specifically to its use for synchrouron injection.
\end{abstract}

\section{INTRODUCTION}

Beam transport at the low energy injoction end of a heavy ion synchrotron is a concern which becomes particularly important for high current beams because of the increasingly important role of space charge forces within the beam [1]. When the beam is tansported through focusing or mass selection elements in which there are transverse magnetic field components, the maintenance of good space charge neutralization may be at risk if the beam suffers from wo great a level of high frequency fluctuation in beam current. Another concern has to do with possible accelerator rf regulation problems that might arise due to fast changes in beam loading during the pulse. Bcam noise is also a detriment to carrying out a wide range of experiments, quice apan from the concer of beam transport. Reproducibility of the beam pulse shape is imponant to the accelerator user and has oearing on the kinds of experimental techniques necessary to collect data. The operational lifetime of the ion source between scheduled mainterance periods and the downtime needed to change ion species are important to the accelerator operations and to the experimenter. The Mevva ion source is a powerful melhod for the production of pulsed, high current beams of metal ions. Here we summarize a range of observations that we have made about its beam noise, pulse shape reproducibility, triggering reliability, lifetime and charge siate distribution.

\section{EXPERIMENTAL BACKGROUND}

The Mevva ion source has been described in detait elsewhere [2-6]. The experiments reported here were carried out both at LEL and GSI. At LBL the Mevva IV ion source embodiment was used; this is a multi-cathode source incorporating 16 separate cathodes in which the operationaI cathode can be changed by rotation of an extemal control knob. The sounce was mounted on a test stand which incorporates magnetically-suppressed Faraday cups for measurement of beam current and a time-of-flight diagnostic for measurement of the ion charge state distribution [7]. Beam extraction voltage was up to $100 \mathrm{kV}$ and the total jon beam curtent was up to $570 \mathrm{~mA}$. Ai GS1 we used a source configuration in which the Mevva cathode stem was atlached to the anode chamber of a CORDIS $[8,9]$ ion source. Beam extraction voltage was up to $35 \mathrm{kV}$ and the beam current measured $50 \mathrm{~cm}$ downstream was up to $40 \mathrm{~mA}$. Experiments have been carried out using both an ion source test stand facility, and the injector tcrminal of the UNILAC heavy ion linear accelerator [10].

\section{RESULTS}

\section{A. Beam Noise}

The beam current fluctuation level varies according to the are current at which the source is operated. There is an optimum operating point at which the rms fluctuation Ievel reaches a minimum, typically about $7 \%$. This opcrating point 
corresponds to the perveance match condition, at which the plasma density (which varies with are current) is optimally matched to the extraction optics [11]. This optimum occurs for an are current of about $100 \mathrm{~A}$ for the ion source used, and is only weakly dependent on metal species employed. Figure 1 shows a typical beam pulse for $\mathrm{Ti}$ at the optimum current level. Figure 2 shows the variation of beam noise as a function of arc current for a titanium beam. The GSI experiments found no difference in beam noise whether or not magncls werc instalicd in the CORDIS multipole structure (12).

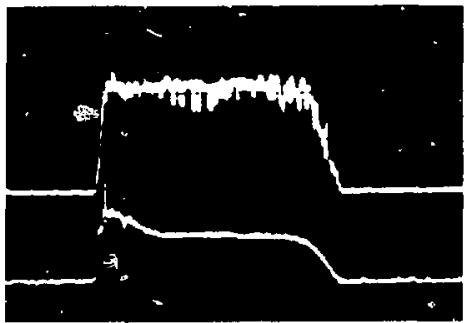

Fig. I Beam current pulse at perveance match. Upper trace: Ibeam, $100 \mathrm{~mA} / \mathrm{cm}$; Lower trace: $\mathrm{J}_{\text {are. }} 100 \mathrm{~A} / \mathrm{cm}$, Swcep speed is $50 \mu \mathrm{s} / \mathrm{cm}$. 'Titanium beam. (XBB 890-9887)

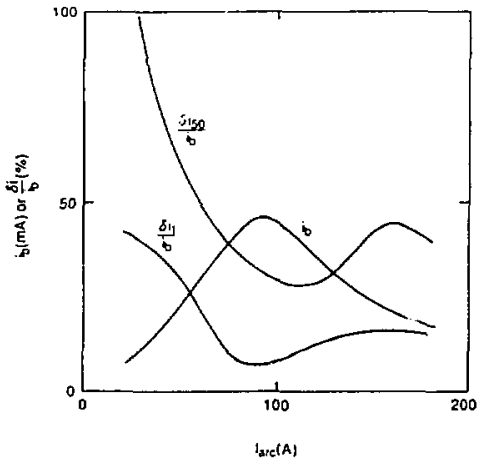

Fig. 2 Beam current $j_{b}$, fractional rms noise measured on a single-shot basis, $\delta i_{1} / i_{h}$, and the fractional rms ncise measured for a sequence of $\mathbf{5 0}$ conscculive shols, $\mathbf{\delta i} 50 / \mathrm{ib}$, as a function of arc current. Titunium beam. Current measured $75 \mathrm{~cm}$ downstream from ion source by a $5-\mathrm{cm}$ diameler Faraday cup. (XBL 8911-7325)

\section{B. Shot-1o-Shot Reprodecibility}

Variation in pulse shape from one pulse to the next is another pcriormance characleristic that is important. Typical Mevva perlormance in this respect is shown in Figure 3. Here the oscilloscope was in "envelope mode" and thus recorded the cnvelope of pulsc shape extrcma for a succession of 50 beam pulses. The pulse amplitude varies from one pulse to the next by the extent indicated. Note that there werc no missing pulses.

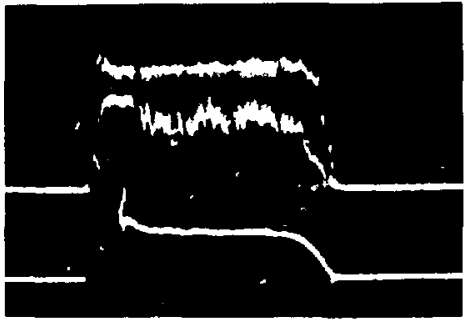

Fig. 3 Shot-to-shot variation in beam current at perveance match. Upper trace: Ibeam, $100 \mathrm{~mA} / \mathrm{cm}$, this is the trace obtained when the oscilloscepe is operated in envelope mode for 50 consecutive shous. Lower trace: $I_{\text {arc. }} 100 \mathrm{~A} / \mathrm{cm}$. Sweep specd is $50 \mu s / c m$. Titanium beam. (XBB 890-9887)

\section{Triggering Reliability}

It is important that the source trigger reliably for a large 'jumber of pulses before it must be removed for maintenance. The triggering failure race should be sinall. We have found that when the trigger pulse is electrically adequate (peak voltage and lolal encrgy are the important parameters) and the trigger isself (annular alumina insulator) in good shape, then the triggering reliability can be excellent. As examples, the following triggering statistics were recorded for recent runs:

Cathodi
Pt
Pd
Ti
Ti
Ti

$$
\begin{gathered}
\text { Tolal pulses } \\
10,000 \\
10,000 \\
10,000 \\
100,000 \\
200,000
\end{gathered}
$$

$$
\begin{aligned}
\multicolumn{1}{c}{\text { Misfires }} \\
4 \text { per } 1000 \\
0 \text { per } 1000 \\
1 \text { per } 1000 \\
10 \text { per } 1000 \\
6 \text { per } 1000
\end{aligned}
$$

Herc "misfires" means the fraction of missing pulses (Failure to produce a bam pulse when trigser pulse is applied). and "total pulses" means the number of pulses actumulated prior to making the misfircs measurcment. Somc cathole matcrials (c.g., Mo) ure difficult to make trigger reliably at arc custent Iess than several hundred amperes. 


\section{Lifesime}

The time for which the source can run between recessary maintenance periods is decemined by die noed for cathode replacement. Under typical operating conditions we obtain up wo several hundred thousand pulses before the cathode is eroded away enough to require change. For the multi-cathode source embodiments (Mevva IV has 16 cathodes and Mevva $V$ has 18) one can simply swilch to another cathode at will, and in this way the total number of shots can be extended up to several million before needing 10 replace all the cathodes in the cathode assembly. At a pulse rate that might suit synchrotron application, say 4 pulses per second, the source can thus be run steadily 24 hours per day for a duration of order a week between changes. Cathode assemblies can be changed in an up-to-air time of less than a minute.

\section{E. Charge Stase Distribution}

The ions generaled are in general muttiply-stripped with a mean charge state of from 1 to 3 , dopending on the particular metal species, and the charge state distribution can have components from $Q=1+$ to $6+$. This means that the ion encrgy is greater than the extraction voltage by a factor equal to the charge statc; for $100 \mathrm{kV}$ extraction voluge the beam can thus be of mean energy up to $300 \mathrm{keV}$ and can have components with energy up to $600 \mathrm{keV}$. Lower $Z$ and lower boiling point metals tend to have lower mean charge state. An empirical expression that we have found to provide a reasonable predictor for the mean charge state (referred to the distribution in particle current) is

$$
\overline{\mathrm{Q}}_{\mathrm{p}}=0.38\left(\mathrm{~T}_{\mathrm{BP}} / 1000+1\right)
$$

where $T_{B P}$ is the boiling point of the metal in " $C$. We have studied the charge state distributions in detail and the results have been reported in the literature [13-15].

\section{CONCLUSION}

The Mevva ion source provides a means for the production of high curnent beams of metal ions that can be useful for accelerator injection, particularly for heavy ion synchrotrons. When the source is operated appropriately ("tuned" corietly) and triggered properly, characteristics such as beam noise, shot-to-shot pulse reproducibility, triggering reliability and lifetime can be excellent. The muluply-chargad ions produced offer an advantage in beain energy for given extraction voltage.

\section{P.CKNOWLEDGEMENTS}

This work was undertaken as part of an ongoing coltaboration between the Lawrence Berkeley Laboratory and the Gesellschaft für Schwerionenforschung. That pan of the work that was carried out at LBL was supported in part by the U.S. Army Rescanch Office under Contract No. ARO 116-89, the Office of Naval Research under Contract No. 88-F-0093, and the U.S. Department of Energy under Contract No. DEAC03-76SFO0098.

*Present address: SODERN, 1 Ave. Descantes, 94451 LimeilBrevannes, France. Supported at LBL by a grant from the French Ministere des Affaires Etrangeres, Bourse Lavoisier, and a grant from SODERN.

\section{REFERENCES}

1. See for instance A. J. T. Holmes, in "The Physics and Tecthnology of ken Sources", edited by I. G, Brown (Wiley. N.Y., 1989), p. 53.

2. I. G. Erown, in "The Physics and Technology of lon Souress", ediled by I. G. Brown (Wiley. N.Y.. 1989), p. 331.

3. 1. G. Brown, J. E, Galvin and R. A. MecGill, Appl. Phys, Lett. 47,358 (1985).

4. 1. G. Brown, J. E. Galvin, B. F. Gavin and R. A. MacGill, Rev. Sci. Instrum. 52, 1069 (1986).

5. I. G. Broun, R, A. MacGill, J. E. Galvin and R, T. Wright, 1987 Particle Accelerator Conference, Washington, D.C., March 16-19, 1987; Proceedings pub, by IEEE, New York. Cetalog No. 87CH2387.9, p. 343 (1987).

6. See, for instance, Rev. Sci. Instrum. 61, 577-59), (1990).

7. 1. G. Brown, J. E. Gaivin, R. A. MacGitl and R. T. Wright, Rev. Sci. trsirum. 58. 1589 (1987).

8. R. Keller. Proceedings of the 1986 Linear Accelerator Conference, Stanford, CA; Report SLAC-303. Stanford, (1986), p. $2 \% 2$.

9. R. Keller, GSI Scientific Report GSI-81-2 (1981), p. 263.

I0. P. Spudike H. Emig, J. Klabunde, D. M. Rutk, B. H. Wolf and I. G. Brown, Nucl. Instr. and Meth. A279. 643 (1989).

11. T, S. Green, Rep. Prog. Phys, 371257 (1974).

12. I. G. Brown, P. Spydike, H. Emig. D. M. Ruck and B. H. Wolf, Nucl. Instr. Meth. A295, 12 (1990).

13. I. C. Brown, E. Feinberg and J. E. Galvin. J. Appl. Phys. 6 3. 4889 (1988).

14. I. G. Brown and J. E. Galyin, IEEE Trans. Plasma Sci. PS-17 $679(1989)$.

15. K. G. Brawn and $X$. Gedechor, paper presented at the 14 th intl. Symp. on Discharges and Electrical Insulation in Vacuum, Santa Fe, NM. September 16-20,1990; $\omega$ be published in IEEE Trans. P!ısma Sci, (1991). 